\title{
Water is Life: Situation Analysis of Access to Household Water Supply in the Wa Municipality, Ghana
}

\author{
Enoch Akwasi Kosoe, Issaka Kanton Osumanu \\ Department of Environment and Resource Studies, University for Development Studies, Wa, Ghana
}

Email address:

ekosoe@uds.edu.gh (E. A. Kosoe), kosumanu@uds.edu.gh (I. K. Osumanu)

\section{To cite this article:}

Enoch Akwasi Kosoe, Issaka Kanton Osumanu. Water is Life: Situation Analysis of Access to Household Water Supply in the Wa Municipality, Ghana. International Journal of Environmental Protection and Policy. Vol. 3, No. 1, 2015, pp. 1-13.

doi: $10.11648 /$ j.ijepp.20150301.11

\begin{abstract}
Far too many people in urban Ghana live without access to safe drinking water and this is a primary determinant of continuing poverty. Using questionnaire survey and key informant interviews, this study explored the situation of households' access to potable water supply in the Wa Municipality, a low-income urban area in north-west Ghana. This study highlights several important issues on access to water supply focusing on availability, accessibility and cost. A clustered sample of residential areas of the municipality was employed and the study was able to examine spatial disparities in access to water supply. The results indicate that access to potable water supply in the municipality is generally high as only 13 percent of households depend on open wells as their main source. Also, the private sector (individuals and non-governmental organizations) are major players in public water supply in the municipality. In spite of the progress made in access to potable water supply, distance and cost of water remain serious challenges confronting households. The study recognizes that private individuals create additional water facilities to augment public supplies, but the positive impacts on health and livelihoods could be greater if access to finance could be facilitated. Most importantly, water supply improvement strategies should incorporate an integrated vision, which sees adequate and quality water both as a goal in itself and as a contributor to economic and social development through gains in public health.
\end{abstract}

Keywords: Accessibility, Health, Households, Urbanization and Water Supply

\section{Introduction}

The importance of adequate water quantity for human health has been recognised for many years and there has been an extensive debate about the relative importance of water quantity, water quality, sanitation and hygiene in protecting and improving health $(1-3)$. In spite of this recognition, international guidelines or norms for minimum water quantities that domestic water supplies should provide for households remain largely lagging. For instance, whilst the Millennium Declaration Goals included a target to halve the proportion of people who are unable to reach or to afford safe drinking water by 2015 (4) it did not specify in what quantity such water should be supplied (5).

Municipal water supply involves a great expense of time and energy, especially for those who have no water sources in or near their homes (6). This is because in many urban areas in developing countries, public water providers have failed to provide households with adequate water supply $(7,8)$. This failure has been attributed to low-quality and inadequate coverage, poor cost recovery, high labour cost and low labour productivity, and large state subsidy (9). But it has also been argued that public water providers give poor services because of political involvement in the sector (10). Again, (11) stressed that population growth, rapid urbanization, inadequate levels of economic development and the absence of appropriate management and technical capacities meant that an increasing number of urban population do not have access to water.

In Ghana, WHO/UNICEF has indicated that the country has achieved and exceeded its 2015 national MDG target of $78 \%$ for water coverage by $6 \%(12)$. But this does not reflect in low-income urban areas $(13,14)$. It is estimated that about 3.5 million people, many of whom are in low-income urban communities, still do not have improved sources of drinking water (14). Also, urban households do not have water flowing regularly through their taps from the municipal water supplies and have to supplement their limited supply with water from other similarly unreliable sources (2015). This 
has led to public water rationing, forcing urban residents to resort to private suppliers $(16,17)$. The water sector in Ghana has been constrained by interlinked political, administrative, economic, social and legislative factors (18). These factors, however, hinder a working water supply system in the country (19). Also, the high cost of treatment of water, high maintenance cost of water plants and equipment, water losses during distribution, increasing population and non-payment of water bills by consumers account for the country's public water sector inability to supply adequate water to their clients (20). Compounding the problem is the inability of the public water system to meet the increasing water demands with respect to deficiency in water quality and quantity, as well as unaffordability and inadequate investment in water infrastructure $(16,17)$. This has led to the involvement of the private sector to improve water supply services in the country but this move, in itself, is not a panacea to the problem of inadequate household water supply $(18,19)$. The issue of privatization has been controversial because consumers do not understand why companies should make profits out of a basic necessity (21). The real issue is better management and efficient delivery of clean drinking water. The political will for reform is essential, but the responsibilities of government agencies for supplying water have not been defined clearly. Partnerships between the government, government agencies and citizens meant to create awareness of water issues, ranging from fighting corruption, conservation and reaching consensus on appropriate water rates, to creating laws to protect resources and mechanisms to resolve water disputes have equally failed to achieve good results (22).

In this paper we present the findings of a water survey which was designed specifically to assess the situation of household access to water supply in the Wa Municipality of North West Ghana. The resulting data, together with information drawn from relevant literature, are used to explore some of the issues and concerns that have been raised with respect to access to water supply in low-income urban areas of developing countries. Here we focus on three main issues. First, we consider the spatial distribution of potable water sources within the municipality. Second, we highlight what constitutes safe access to water and its relevance to households. Third, we examine water availability and cost in relation to the various potable water sources.

\section{The Urban Water Supply Challenge in Context}

Water is key to urban life. While access to water supply improves health, it also has implications for a number of other development goals (Figure 1). According to the 2003 World Water Development Report (6), problems of poverty are inextricably linked with those of water - its availability, proximity, quantity and quality - and as such improving access to water could make a major contribution towards achieving the eradication of extreme poverty and hunger. Moreover, improved access to water supply directly affects sanitation and hygiene and indirectly reduces mortality rate amongst the under fives. Given that an estimated 88 percent of diarrhoeal diseases - the second leading cause of death in the under fives - can be attributed to unsafe drinking water, inadequate sanitation and poor hygiene (23), improving access to safe water (and sanitation) will be central to mortality reduction.

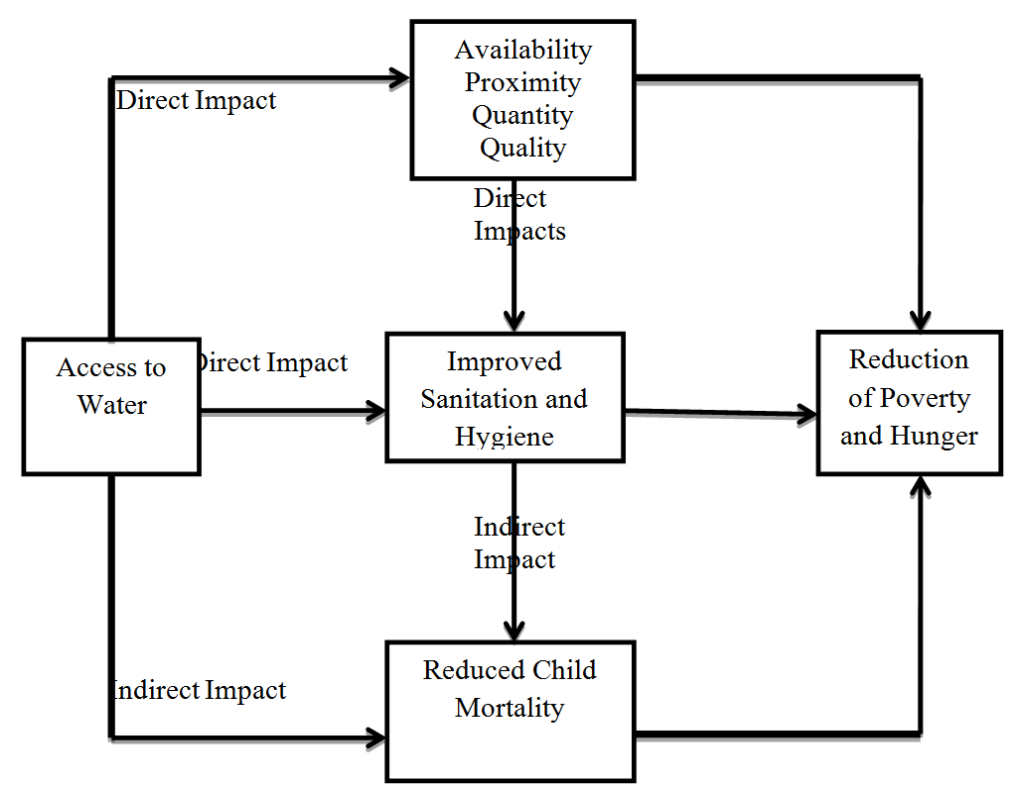

Figure 1. Impacts of access to water supply.

Although access to safe drinking water can have a strong positive effect on human health and well-being, the development and management of water resources as a whole also has significant health implications, usually a combination of negative and positive (23). The balance between these effects, and protection of the health of vulnerable groups, is in the hands of those who plan and implement interventions, which can be strongly influenced 
by the health sector and health arguments. It has been noted that, in most low and middle-income countries, there is virtually no reliable information on who has safe drinking water; there are merely estimates of the percentage of the population - total, rural and urban - who have access to an improved water source (24). Going by the currently accepted definition, individuals are deemed to have access to an improved water source if they have a household connection or access to a public standpipe, borehole, protected well, protected spring or rainwater collection facility, capable of providing 20 litres per capita per day, at a distance of not more than $1,000 \mathrm{~m}$. An unimproved source is taken to be any unprotected well or spring, vendor-provided water, tanker truck provision of water and bottled water (25). The latter is considered to be unimproved owing to concerns over the quantity of supply and not its quality.

One of the problems is that the accepted definition places the emphasis on the quantity of water and the distance to source, but makes no provision for the important aspects of quality, regularity of supply, cost, or the number of people using the source. As such, having a source of water close by does not necessarily mean that an individual has access. WHO/UNICEF acknowledge that the definition of an improved water source is problematic and that the assumption that certain technologies are better for health than others may not be true in all cases, noting that "in some locations an unprotected household well may provide a better supply of water, both in terms of quantity and quality of water, than a household connection which may be subject to intermittence and poor water quality" (26). Another problem is that in urban areas, rapid population growth and migrations motivated by cultural, economic, political, and environmental factors strain existing water infrastructures and create enormous problems in planning and constructing new infrastructure. Residents of many of the low-income cities enjoy only intermittent access to piped water, often of dubious quality and only from public taps at substantial distances from their homes. Others depend on water vendors for small volumes of costly water of unsure quality. Where providers cannot guarantee water quality at the point of supply, or where it cannot be guaranteed at the point of use, because of contamination during collection, transport, and storage, consumers face significant health risks.

Given the failure to reduce the numbers of people without access to basic water supply during the 1990s, and the financial implications of even the apparently modest international development target of halving the proportion of people not served with improved drinking water by 2015, it is evident that "business as usual" cannot provide a satisfactory response. Approaches that rely solely on time and resource-intensive centralized solutions will leave hundreds of millions of urban residents in developing countries without access to safe water far into the foreseeable future. There should be an outcry for immediate, concerted efforts to confront the reality that water supply coverage rates in the developing world barely keep pace with population growth.

\section{The Study Area and Methodology}

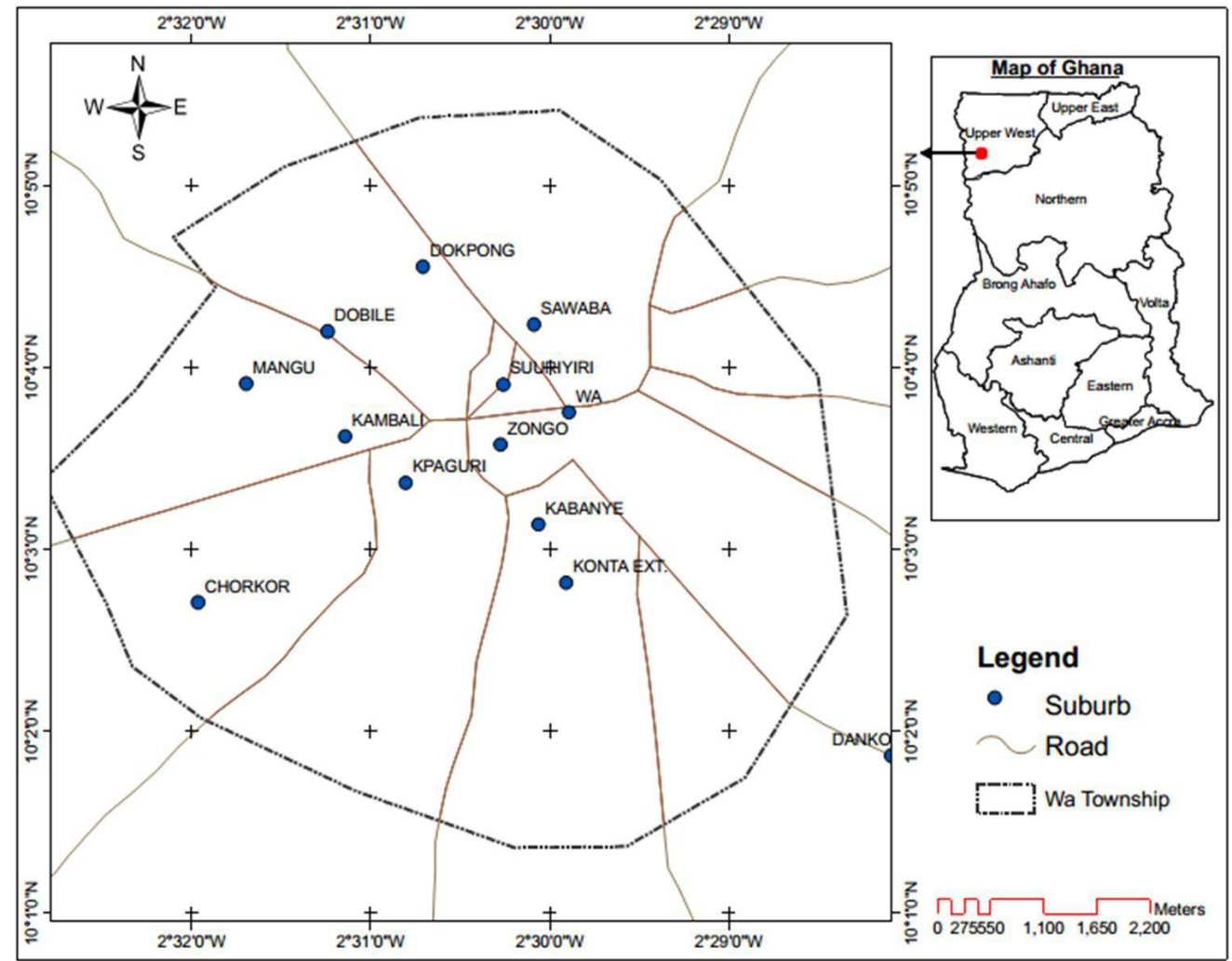

Figure 2. The study context. 
The locational context of this study is Wa, which is the regional capital of the Upper West Region of Ghana. Wa lies between latitude $1^{0} 40^{\prime} \mathrm{N}$ to $2^{0} 45^{\prime} \mathrm{N}$ and on longitude $9^{0} 32^{\prime} \mathrm{W}$ (Figure 2), thus covering an area of approximately 1,180 square kilometres, which is about 32 percent and 2.56 percent of the region and nation respectively. Wa's population was estimated to be 135,638 (Female 65,887 / Male 69,751 ) by the year 2010 with a growth rate of 2.7 percent per annum (27). The spatial distribution of the population displays a typical character of a young municipality - a heavy concentration of population in Wa town surrounded by smaller towns and rural settlements. Using the 2010 Population and Housing Census (27) figures, Wa's population is 50 times higher than the next populous settlements (Busa, Sagu, Charia, Kperisi and Boli) each with populations below 3,000 people. The significance of this type of distribution is that Wa town provides the highest level services (first level services and functions) in health, education, finance, administration of justice and security, commerce and transportation, amongst others, to its hinterland and patent services for resource mobilization, peace building and community needs identification.

Apart from the use of documented sources, the study also generated first-hand information from the field. The study relied on qualitative and quantitative approaches taking into consideration the data demands of the study. Household questionnaires were used as its primary data collection instrument. This approach is deemed appropriate when the object of the research is to explore attitudes or reactions of a group or community in response to some commonly experienced aspects of their environment. Through such interactive discourse, participants are able to offer insights on the perspective of the enterprise, revealing clues to the social contexts that shape their opinions. In all, One hundred and fifty-four respondents were interviewed using the household questionnaires.

A two-stage sampling methodology was adopted in the selection of households for the interviews. The first stage was the clustering of residential areas according to town planning classifications into three core zones. Zone One covered the unplanned residential areas, which covers mainly the traditional settlements before urbanization and their immediate surroundings. Zone Two is made of the planned suburbs which have most government bungalows and private residential apartments occupied mainly by high and middle class households. Zone Three comprises the Newly Developing Areas, part of which is made of the surrounding villages which have been absorbed into the urban agglomeration as a result of urban sprawl. Since households in Zone One are more extensive than in Zones Two and Three, 40 percent of the total sample was apportioned to Zone One and 30 percent each to Zones Two and Three. Within the selected residential areas, blocks were created based on the number of houses and interviewers selected households to interview by systematically walking through the blocks and interviewing one household in every tenth (for
Zone One) and twentieth (for Zones Two and Three) house. The questionnaires were administered to household heads or their representatives. In a house where there were multiple households, only one household was interviewed.

In addition to the household surveys, in-depth interviews were organized with Ghana Water Company Limited (GWCL), Community Water and Sanitation Agency (CWSA), Private Water Providers and the Wa Municipal Assembly. Purposive sampling was used to select staff of these institutions and agencies. This is because these are officers knowledgeable in issues related to water supply and management. The interviews covered themes on the number of water provision facilities and their distribution within the municipality to enable the spatial mapping of the facilities as well as their detailed knowledge about the enterprise.

Hand-held global positioning system (GPS) receivers were used to pick geographic coordinates of various water points used by GWCL and other water facilities in the municipality. The coordinates were taken in the Degree Minute Second (DMS) format. These were converted to Decimal Degree (DD) in Microsoft excel spreadsheet using the formula: $=D+\frac{M}{60}+\frac{S}{3600}$, where $\mathrm{D}=$ Degree, $\mathrm{M}=$ Minutes and $\mathrm{S}=$ Seconds. The coordinates were imported to ArcMap software and converted to a Shapefile. The projection parameters were changed from the default World Geographic System 1984 (WGS 84) to projected Universal Transverse Mercator Zone 30 North. It was then overlaid with existing country Shapefiles and layout maps were produced showing how the various water points are spatially distributed within the municipality.

\section{Results and Discussions}

\subsection{Spatial Distribution of Potable Water}

The main water sources used by households in the Wa Municipality are boreholes both non-mechanized and mechanized (sometimes supplied through public taps), open wells and piped water from the Ghana Water Company Limited (GWCL). Of the households interviewed, 42 percent depends on public taps supplied by mechanized boreholes for their water needs whiles 12 percent gets their water supply from GWCL's Services. The distribution across residential zones depicts a high concentration of piped water in Zone Two and boreholes in Zone Three (Figure 3). Respondents assigned a number of reasons for their main water source ranging from being the only water source available in the community to being the cheapest. Besides the open wells, all the water sources are potable and this presents a much better picture compared to other towns in Ghana. This confirms the conclusion of the 2008 Ghana Demographic Health Survey (28) that the Upper West Region has the highest potable water coverage in Ghana. This finding also indicates a possible good health status for households in Wa. 


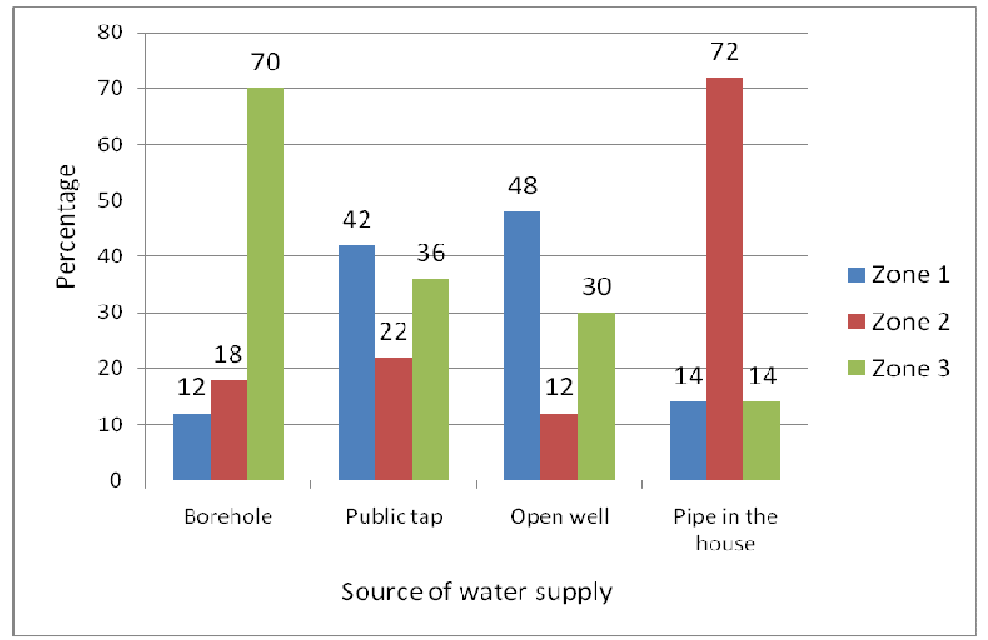

Figure 3. Source of water supply for households by residential zones (\%).

The Ghana Water Company Limited has 16 boreholes (Figure 4) from which they serve the whole of the Wa Municipality with potable water. These 16 boreholes are able to generate and distribute $1,000 \mathrm{~cm}^{3}$ to its customers (including households, institutions and business establishments). From Figure 4, it can be observed that five of the boreholes are located at the outskirts of Wa Township.
These five boreholes have a total generation capacity of 700 $\mathrm{cm}^{3}$ whiles the other 11 have a total generation capacity of $850 \mathrm{~cm}^{3}$. The water company has two water storage facilities in the municipality - a concrete water tank and a steel water tank. The two have a combined storage capacity of $2,091 \mathrm{~cm}^{3}$ made up of $1,818 \mathrm{~cm}^{3}$ and $273 \mathrm{~cm}^{3}$ respectively.

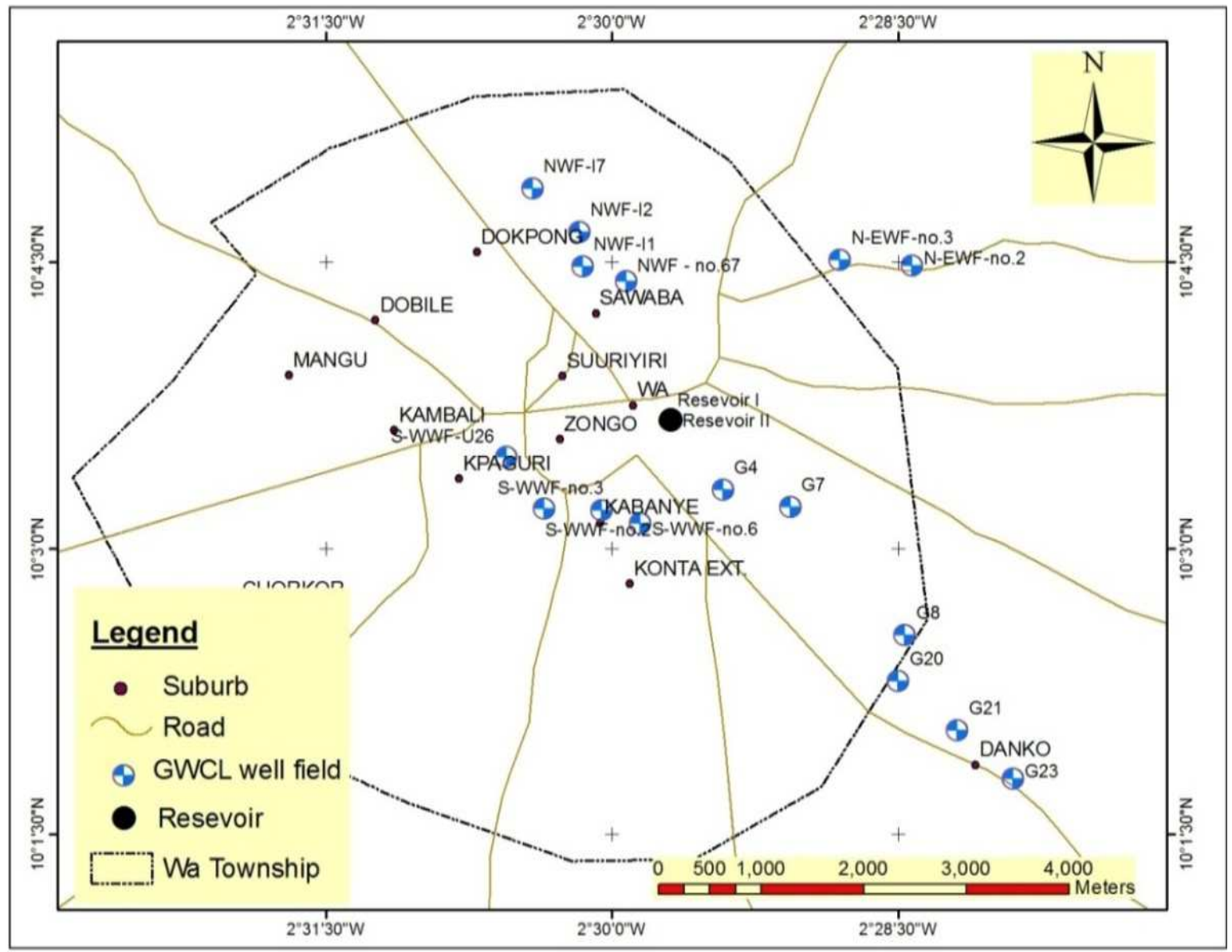

Figure 4. GWCL water points for potable water supply in Wa. 
Though, in terms of numbers, the number of boreholes seems to be adequate, total yield from these boreholes is not able to support continuous supply of water for the municipality. As such the water company is forced to operate a rationing programme, leading to the supply of water once in every four days for different zones. The company has divided Wa into four zones - North, South, East and West for purposes of the water rationing and each zone gets water supply one day in a four-day cycle. The North and South consist of areas comprising settlements in Zone Two, the West is made up of suburbs in Zone One while the East covers parts of Zones One and Three.

Analysis of the household data indicates that only 12 percent of the households interviewed depend on GWCL's water supply service. The low percentage of people patronizing GWCL's service could be a direct fall out of the company's inability to produce enough water to supply the municipality. This is evidenced by the number of boreholes constructed across the entire municipality by the Wa Municipal Assembly (Figure 5), Non-Governmental Organizations (NGOs) and private individuals to provide potable water to residents. The field survey indicated that the Wa Municipal Assembly has constructed a total of 40 boreholes in various locations as shown in Figure 5. Twentyeight boreholes from the total 40 , verified to have been provided by the Wa Municipal Assembly, are nonmechanized whereas 12 are mechanized (see Figure 5). Refreshingly, further enquiry revealed that the assembly has plans to mechanize all the boreholes it has constructed across the municipality to improve potable water service provision. These boreholes are managed by Water Committees (WCs) in the various suburbs. Also, some individuals have constructed open wells in their houses to supply them with water, but most of these wells dry up during the dry season leading to shortage of water during those periods.

Private individuals, unlike the Municipal Assembly, focus mainly on constructing mechanized boreholes rather than non-mechanized boreholes, with as many as 35 privately owned mechanized boreholes mapped in the study as compared to 13 non-mechanised privately owned boreholes (Figure 6). Interestingly, Mangu, a community located in the northern part of the Wa Township (Zone Two), alone accommodates four of the total number of boreholes. Konta Extension, Kpaguri and Dokpong (also in Zone Two) on the other hand have 3,2 and 1 respectively of such boreholes. This in a way is an indication of the uneven spatial distribution of potable water supply in the Wa Municipality which could have a telling effect on the residents of these areas in the long term as the population continues to grow.

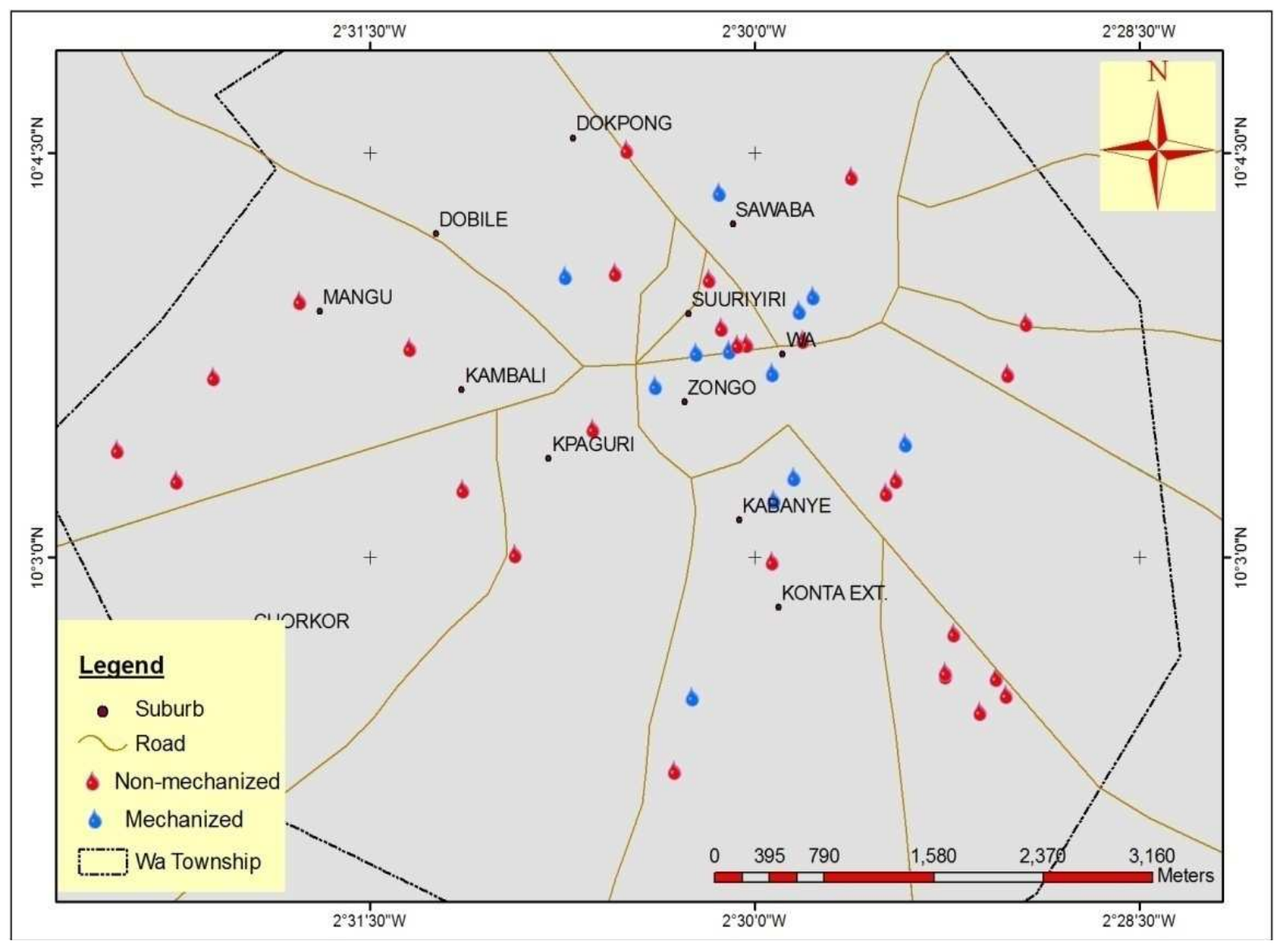

Figure 5. Boreholes constructed by the Wa Municipal Assembly. 


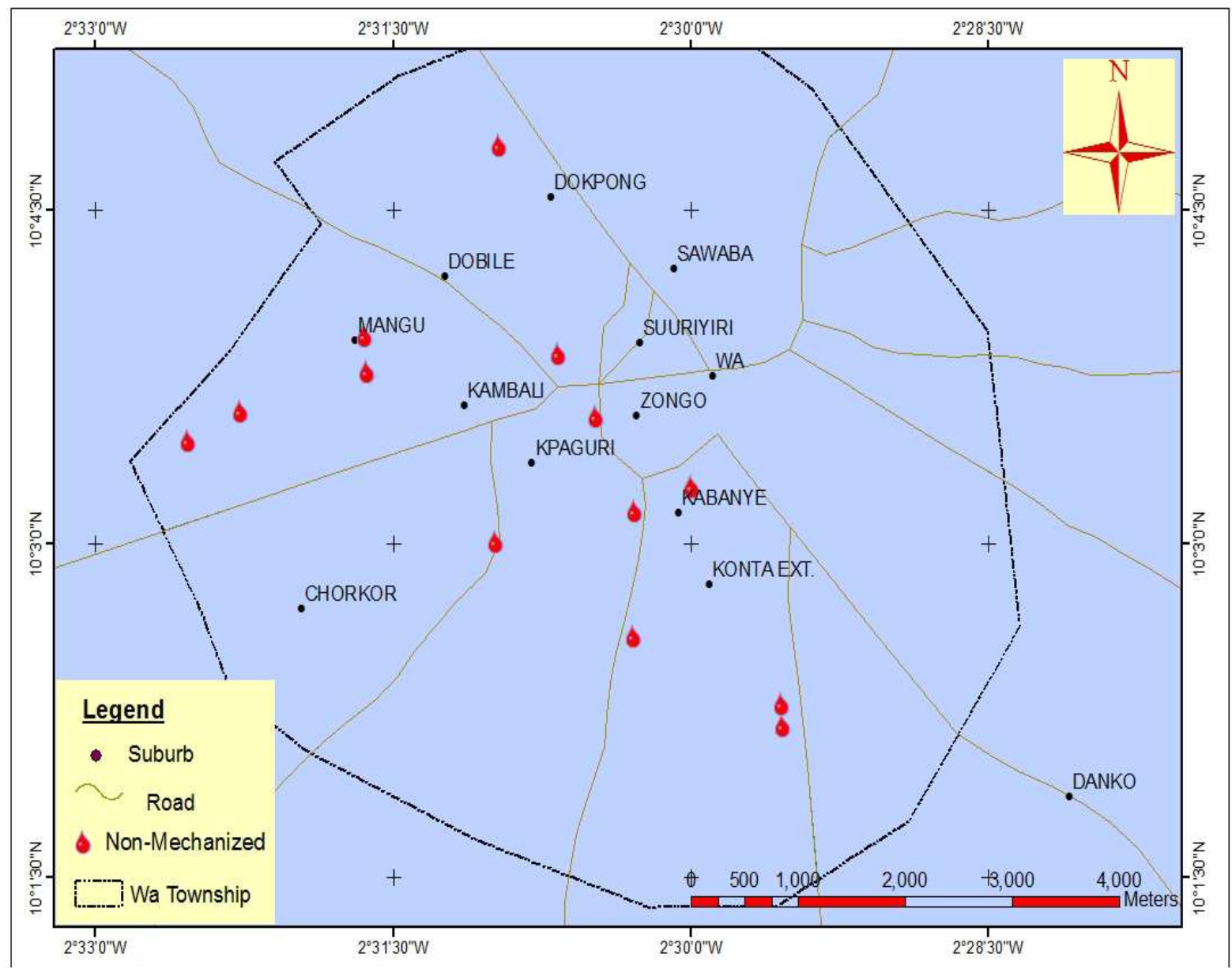

Figure 6. Distribution of non-mechanized boreholes by private individuals.

The household survey revealed that 33.1 percent of households, mainly in Zone Three, depend on nonmechanized boreholes for potable water supply. According to these households, the main reason for their dependence on this source is that non-mechanised boreholes are the only available water sources in their area. However, most of these non-mechanized boreholes have low yields thereby affecting the quantity of water used by those households which affects the acceptable minimum use of water of 20 litres per day per person prescribed by the UN. On the other hand, a seemingly positive outcome from the study was that 41.6 percent of the households interviewed depend on mechanized boreholes for their water needs. Reasons assigned by these respondents included water source being closer to their homes, water source being the only available source within their vicinity, and the source being relatively easier to obtain as compared to the non-mechanized boreholes in terms of effort.

Accounting for the spatial distribution of privately mechanized boreholes, it was realized that Kpaguri alone has as much as 31.4 percent of the privately owned mechanized boreholes recorded in the study. In sum, the entire southern part of Wa comprising Kpaguri, Konta Extension, Zongo, Kabanye, Kambali and Chorkor have as much as thirty (30) mechanized boreholes making up a whopping $85.7 \%$ of all privately owned mechanized boreholes in Wa. This is shown in Figure 7. Most of the respondents within the southern part of Wa maintained that their communities were initially not connected to GWCL's services and even in recent years the connectivity is very low. On the other hand, the northern part of Wa comprising Dokpong, Sawaba, Dobile, Suuriyiri and Mangu collectively accounts for only five mechanized boreholes (Figure 7), with most households within these communities being connected to GWCL's services whiles others buy water from vendor-provided services. This is consistent with the views expressed by officials of the Wa Municipal Assembly that in sitting their boreholes, they lay much emphasis on spatial considerations and that accounts for most of their mechanized boreholes (8) being located in the northern part of Wa (Suuriyiri, Zongo, Sawaba and Dobile). 


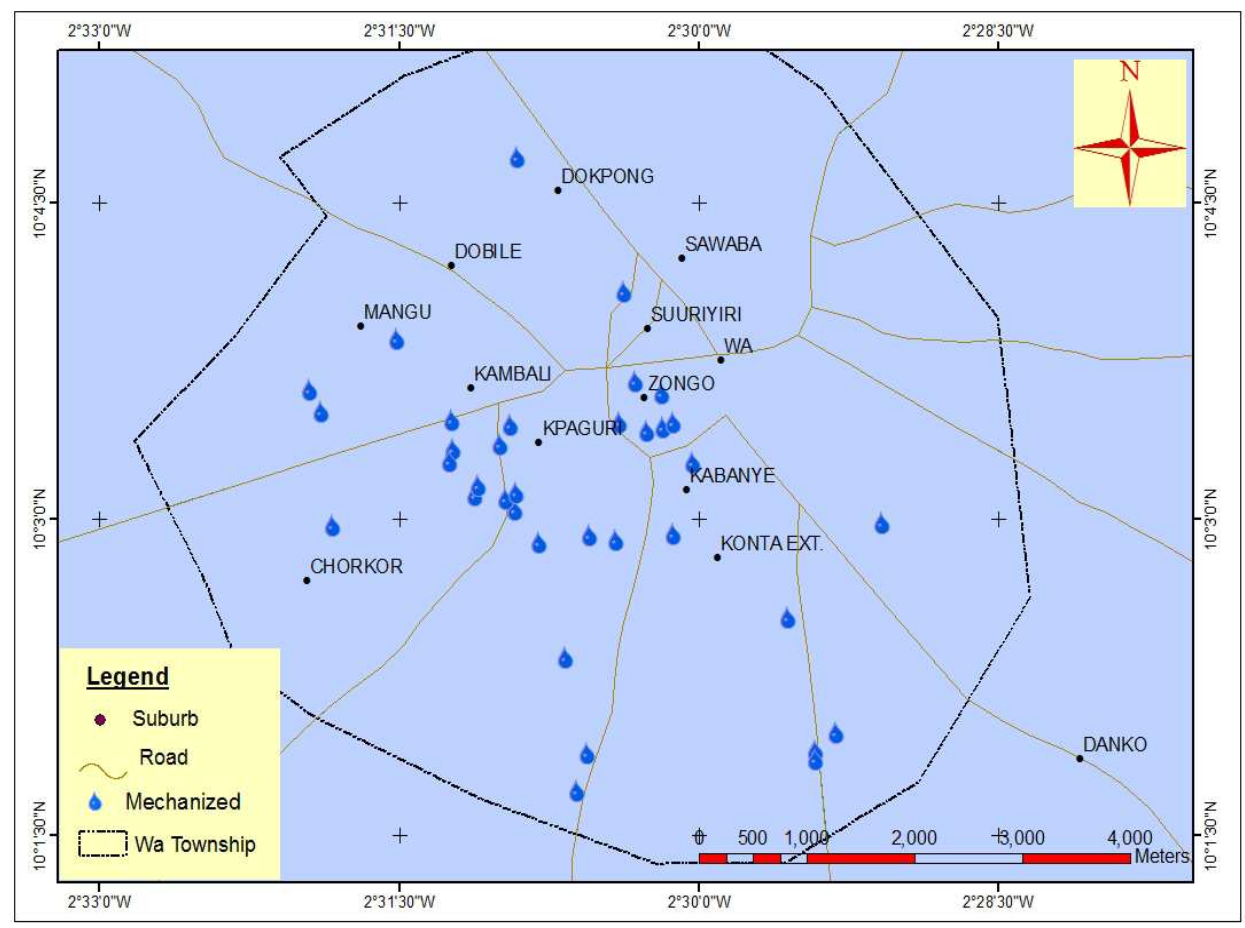

Figure 7. Distribution of privately owned Mechanized Boreholes.

Some respondents revealed that beyond the boreholes and the pipe borne water, other sources of water for their households are over-head storage tanks and open wells. Though the study identified a number of over-head storage tanks constructed to store water for onward distribution to standpipes, toilets, sinks, among others, these storage tanks in strict technical terms are not water sources but rather attachments to other potable water sources. Majority of these storage tanks are plastic tanks erected above the ground and connected to mechanised boreholes by PVC pipes. Water is transported from these through the PVC pipes to the stand pipes for distribution. Some of these over-head tanks also obtain water from tanker services. The distribution of these tanks is also skewed towards the southern part of Wa (Figure 8). A plausible explanation to this skewedness is the fact that most of these storage tanks are constructed as attachments to mechanized boreholes.

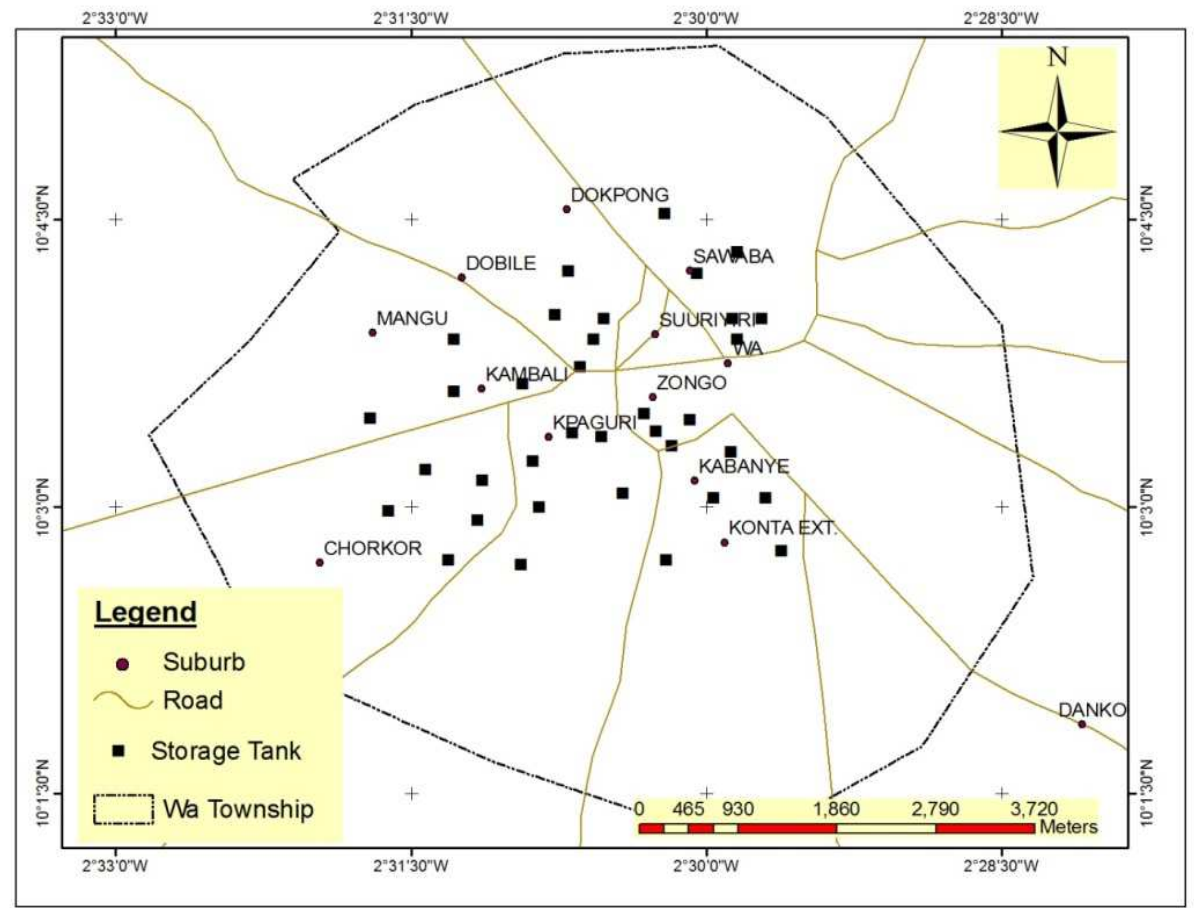

Figure 8. Distribution of water tanks. 
There are 95 open wells constructed across the length and breadth of the Wa Municipality to provide water. Most of these wells are constructed by private individuals and, therefore, are found in individual homes where houses close by these homes also patronize them. Others are also community owned and, therefore, serve the water needs of the entire community. The distribution of these open wells, as depicted in Figure 9, is not even across the municipality. Indeed suburbs such as Zongo, Kambali, and Sawaba (all in
Zone One) have more wells than other areas. Specifically, there are over 40 wells in Zongo, Kambali and Sawaba, as compared to 11 in the other areas. The wells seem to be concentrated around certain areas which may be due to the fact that those areas do not have access to GWCL's services. Another reason is the fact that people in those areas with fewer wells available do not like well water as most respondents saw it as unsafe for drinking.

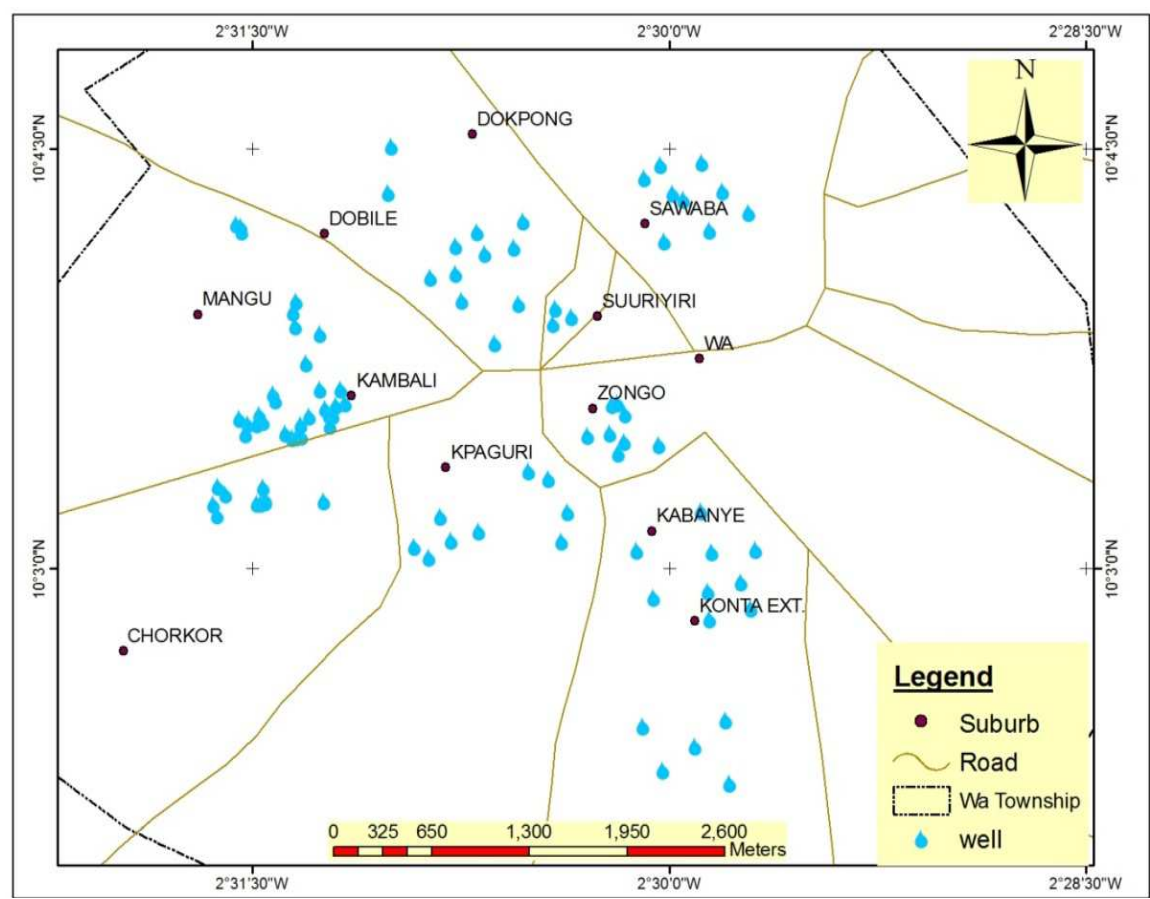

Figure 9. Distribution of wells.

\subsection{Potable Water Availability and Accessibility}

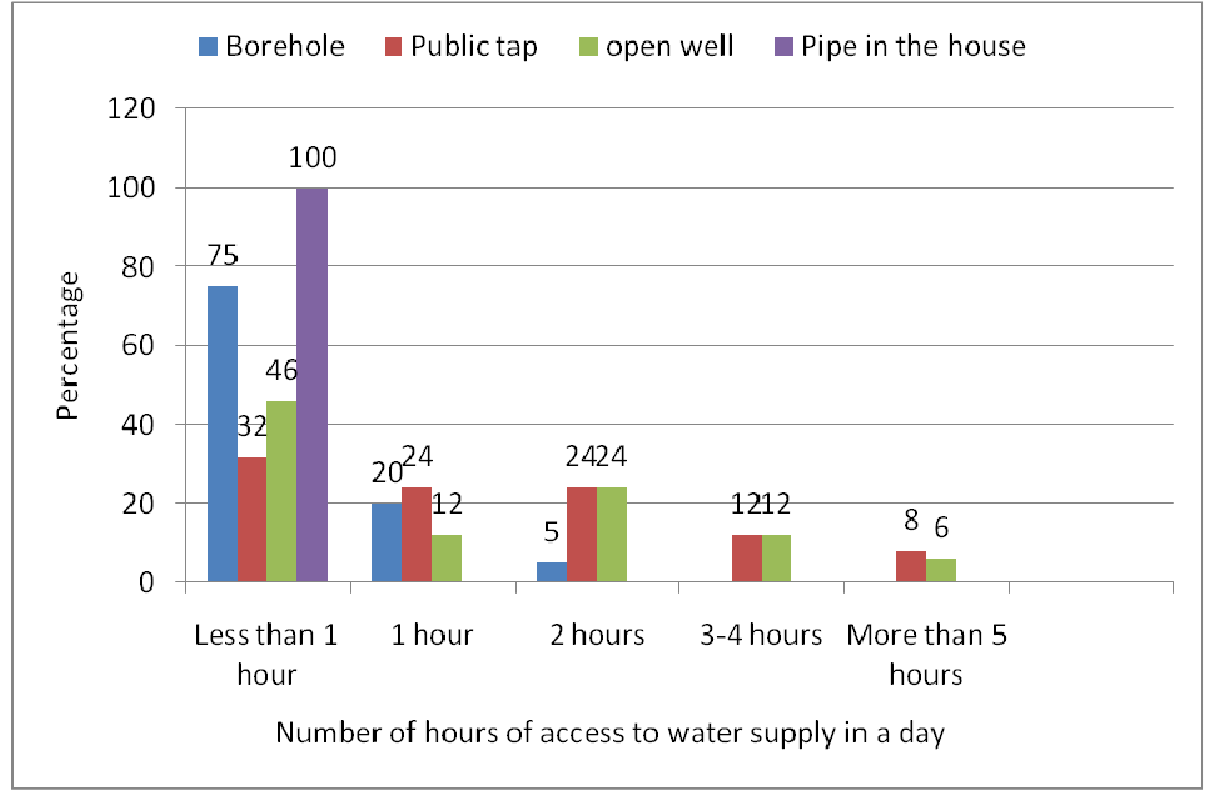

Figure 10. Water availability source of water supply (\%). 
Unlimited access to potable water supply is a pre-requisite to good health and increased productivity thereby reducing poverty in the long run (World Bank, 2006). Accessibility is a concept that has many dimensions and perspectives. However, this study considered accessibility from three perspectives: water availability, cost per unit fetched/used and distance taken to access the water facility. The findings reveal that households are, to a large extent, well placed to increase their productivity as 95 percent of them maintained that water from their principal source was available throughout the year, especially for households with piped water in their homes and borehole users (Figure 10), while the other 5 percent have intermittent water supply, especially during the dry season. This measure of availability took into consideration the number of hours users have access to the water facility in a day and the frequency of breakdown of the water facility.

Though the availability of water on hourly basis seems acceptable, the water availability is also influenced by the number of times the water facility breaks down because it interrupts supply. With as much as 74.7 percent of respondents depending on both mechanized and nonmechanized boreholes as their main source of water supply, the level of availability of water may not be totally optimum all year round considering that these boreholes do break down sometimes in the course of the year. Only 39.1 percent of the respondents indicated that the boreholes from which they obtain water had never broken down within the past one year (Figure 11), whiles the others reported that they have had their main source of potable water breaking down at least once during the past year. The frequency of break-down of boreholes was found out to be a function of whether it is mechanised or not. Though, virtually all boreholes were identified, as a matter of reality, to have the potential to become faulty, non-mechanized boreholes broke down more frequently than the mechanized ones. One major explanation to this occurrence that run through the responses was that the non-mechanised boreholes broke down often due to pressure on them.

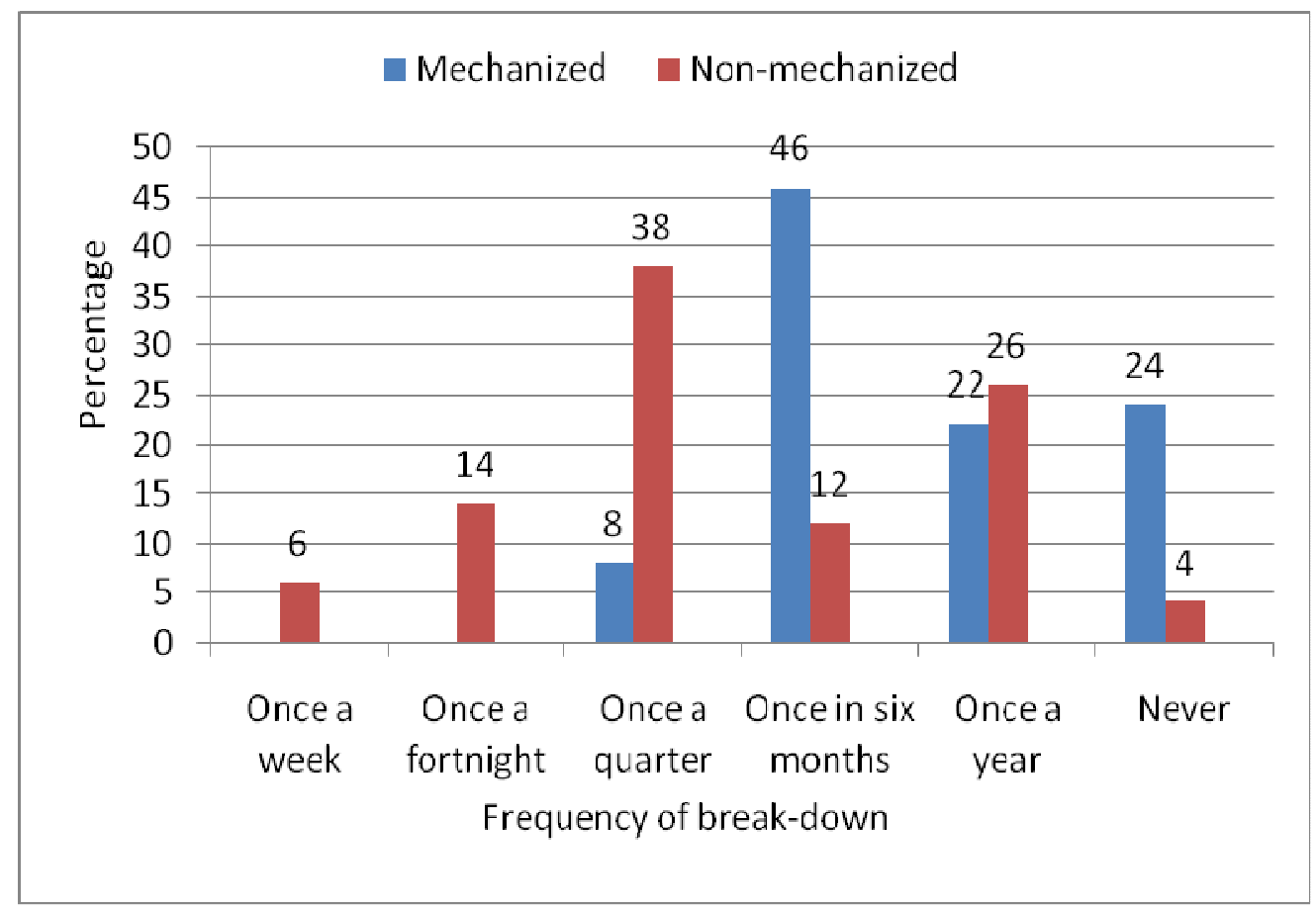

Figure 11. Frequency of boreholes break-down by type (\%).

Cost is also a factor of accessibility and influences water use patterns of households. Where the price of water is considered to be cheap, the usage rate is higher and where the cost is seen as expensive, the relative rate of patronage is low (Cairncross, 2000). Respondents in the study mentioned different rates as the cost of water they incur on monthly basis. Contingent on their average monthly income and their household sizes, respondents judged the cost of water to be either cheap or costly, with only 15.7 percent of them indicating that they did not pay for the water they use because their water facilities are provided by NGO's and other development partners, as such it is to a large extent free.
According to them, they only contribute for the maintenance and repairs in the event of break-downs. Similarly, users of open wells do not pay for water. However, 22.7 percent of respondents (borehole users) paid between $\mathrm{GH} \notin 2.00$ and GHф30.00 per month as shown in Figure 12. Unlike users of boreholes, the monthly amounts paid by subscribers of GWCL's services varied drastically, ranging from GH $₫ 5.00$ to above GHф50.00 per month. The highest amounts paid for water were reported by households who obtain water from tanker supplies. Tanker water suppliers charge GHф25.00 for 12 drums of water, which an average household uses for a two-week period. 


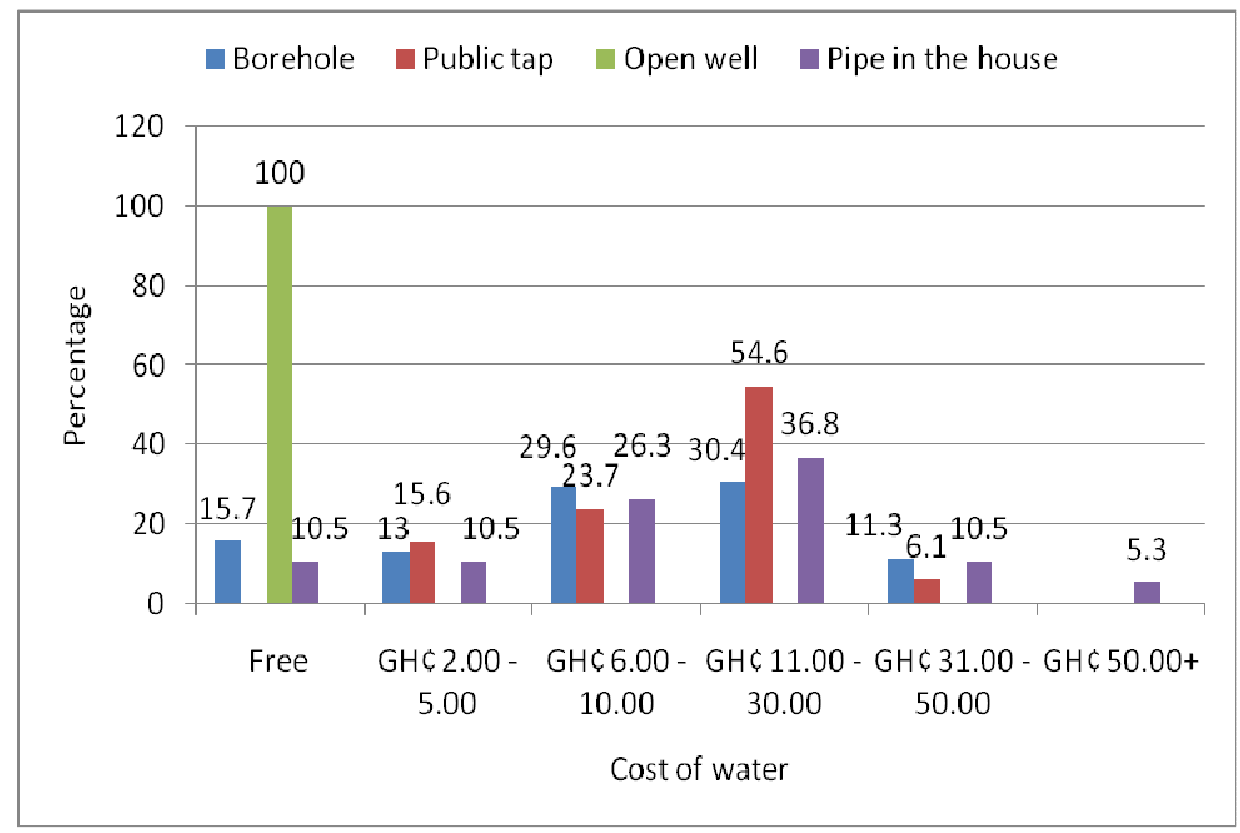

Figure 12. Cost of water per month by source of water supply (\%).

Distance to a water facility and access to the water have an inverse relationship. Thus people's water usage rate is influenced by the distance they cover to access the water (Cairncross, 2000). If people consider the distance to be far, the water they use daily is affected negatively. Apart from those with wells and home connections from GWCL, the average distance covered by households to access water was 125 meters. About 23 percent of households covered 100 meters or less to access water, whiles 24.8 percent covered 300 meters or more to do same (Figure 13).

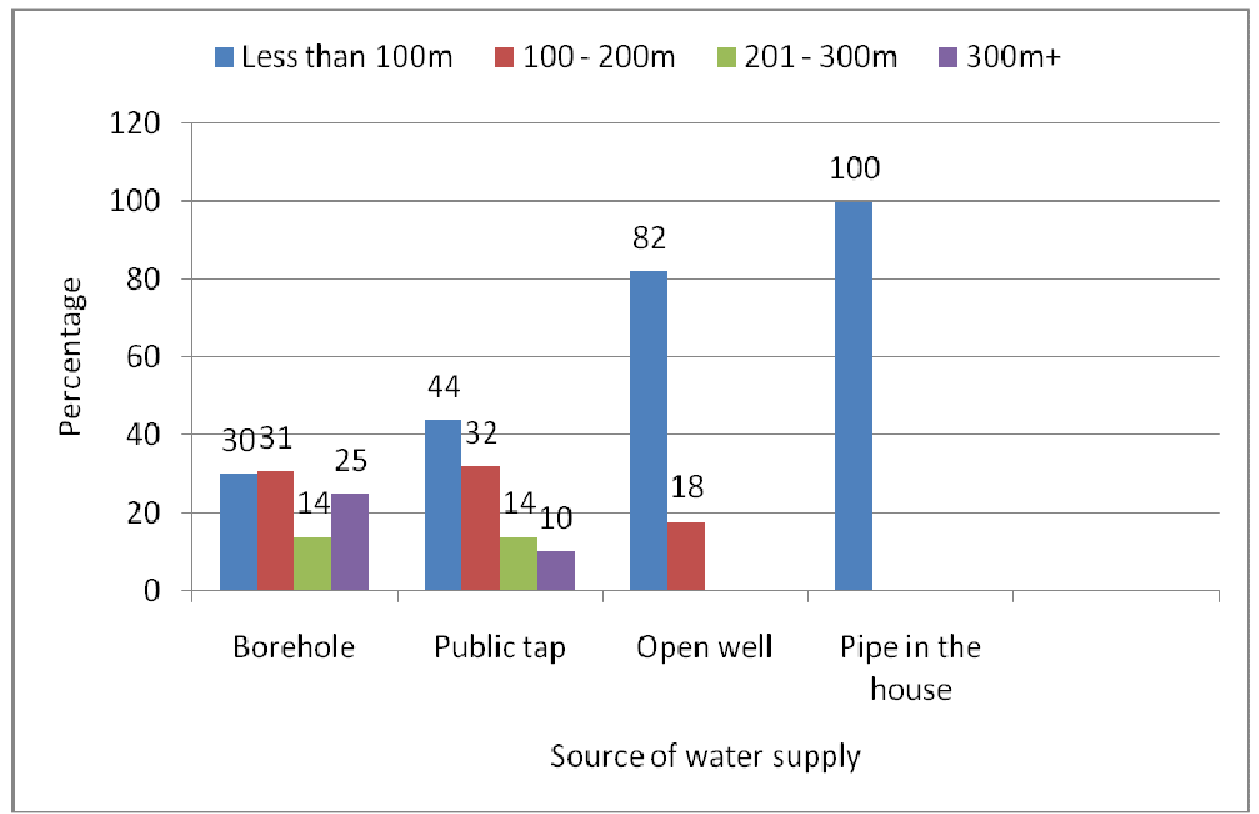

Figure 13. Distance covered to access water by source of water (\%).

Respondents enumerated a number of challenges they face in accessing potable water. These are high cost of water, irregular flow of water, long queues, long distance, longer time taken to repair broken down water facilities and high chemical inputs (for water from GWCL). Figure 14 shows the challenges enumerated by respondents and their respective percentages. 


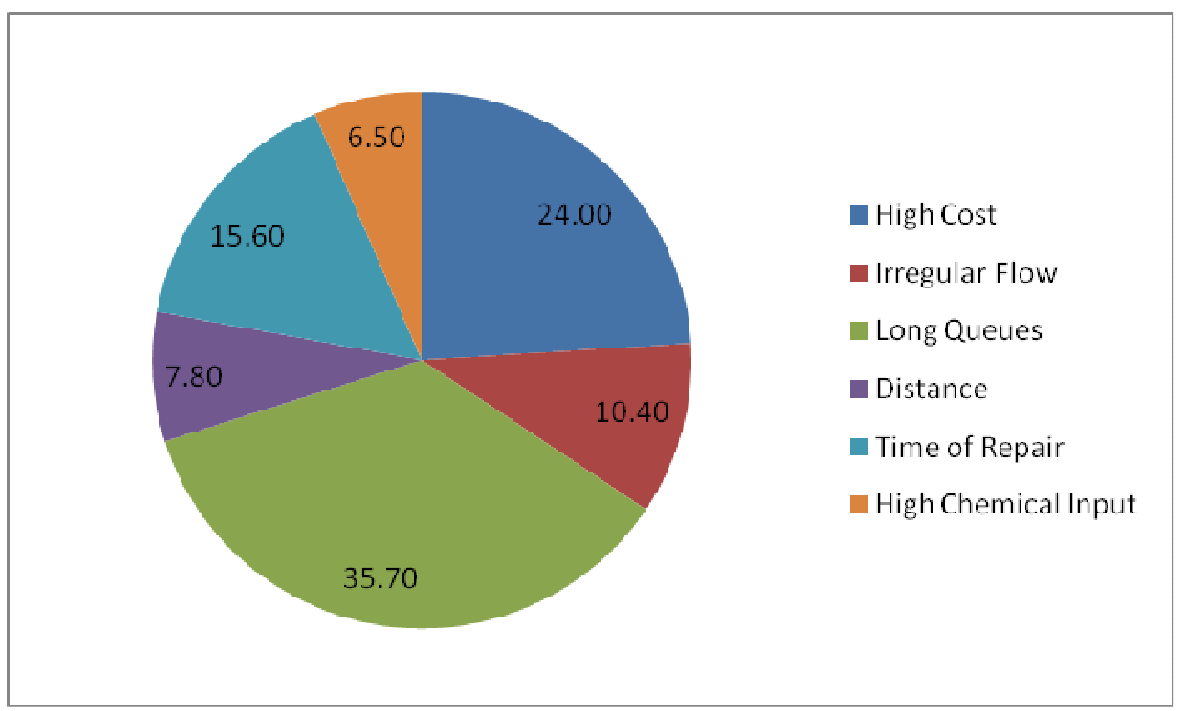

Figure 14. Challenges of accessing potable water (\%).

GWCL is faced with some challenges which prevent it from delivering proper services to its customers and the public as a whole in Wa. Some of the challenges include operating limited number of boreholes (a situation which does not support continuous supply of water), lack of surface water projects and low investment in the water sector. The municipal assembly has some plans in place in addressing the challenges confronting potable water provision which include sourcing funding for the extension of surface water from the Black Volta near the border with Burkina Faso, construction of limited water systems (mechanizing) on existing boreholes and new boreholes, and enforcing by-laws governing drilling of boreholes per the guidelines of the Water Resource Commission (WRC).

\section{Conclusion}

The progress of effective water supply delivery processes in Ghana, as it is in many developing countries, has been stalled by inadequate and inefficient implementation of propoor policies as far too many people in urban areas of the country live without access to safe drinking water. This is a primary determinant of continuing poverty. But the situation in the Wa Municipality seems different as only 13 percent of households in the municipality do not have access to potable water supply. Superficially, this would appear to mean that coverage of water supply in the municipality is adequate, but it is more important to have a look at the situation given the significance of universal access to potable water supply. Especially, the study highlights that issues of distance and cost regarding access to potable water remains a challenge in the municipality. Appreciation of the linkages between water and health is not new. The case is clear and the effectiveness of actions well known. However, in view of the financial constraints and shortages of trained health professionals in a poor area like the Wa Municipality, the issue of access to water supply needs to be given the priority and attention it deserves. This study has highlighted several important issues on access to water supply in low-income urban areas which are different and require different strategies to tackle. Progressive expansion of improved water supplies is important but often fails to address the immediate needs of the most disadvantaged, and cost is always a concern in projects aimed at developing strategies to address these challenges. The findings further reveal that private individuals create additional water facilities to augment public supplies, but the positive impacts on health and livelihoods could be greater if access to finance could be facilitated. Most importantly, water supply improvement strategies should incorporate an integrated vision, which sees adequate and quality water both as a goal in itself and as a contributor to economic and social development through gains in public health. Policy makers must be able to recognize and build on these linkages so that water supply and other policy goals can be made mutually supportive.

\section{References}

[1] Cairncross, A. M. (1990). Health impacts in developing countries: new evidence and new prospects. J. Inst. Water Envt. Mgt. 4(6):571-592.

[2] Esrey, S. A., Feachem, R. G., Hughes, J. M. (1985). Interventions for the control of diarrhoeal diseases among young children: improving water supplies and excreta disposal facilities. Bul. Wld. Hth. Org. 63(4):757-772.

[3] Esrey, S. A., Potash, J. B., Roberts L., Shiff, C. (1991). Effects of improved water supply and sanitation on ascariasis, diarrhoea, dracunculiasis, hookworm infection, schistosomiasis, and trachoma. Bul. Wld. Hth. Org. 69(5):609621.

[4] Sorenson, B. S., Morssink, C., Campos, A. P. (2011). Safe access to safe water in low income countries: water fetching in current times. Soc. Sci. Med. 72:1522-1526.

[5] Howard, G., Bartram, J. (2003). Domestic Water Quantity, Service Level and Health. New York: World Health Organization. 
[6] United Nations (2003). The 1st UN World Water Development Report: Water for People, Water for Life. Retrieved on 16 August $2014 . \quad$ Available: http://www.unesco.org/water/wwap/wwdr/index.shtml

[7] Nickson, A. (2002). The role of the non-state sector in urban water supply. In Paper for the Making Services Work for Poor People. World Development Report (WDR) 2003/04 Workshop, 4-5 November in Oxford.

[8] Mwanza, D. (2004). African Public Utilities not Performing Efficiently. Paper presented at the 12th Union for African Water Suppliers Congress, 16-19 February, 2004 in Accra, Ghana.

[9] Panayotou, T. (1997). The role of the private sector in sustainable infrastructure development. In: Gomez-Echeverri, L. (ed.), Bridges to Sustainability: Business and Government Working Together for a Better Environment. Yale School of Forestry and Environmental Studies Bulletin Series 101. Yale University, New Haven, pp 54-72.

[10] Schwartz, K. H., Schouken, M. (2007). Water as a political good: revisiting the relationship between politics and service provision. Water Pol. 9(2):119-129.

[11] Biswas, K. A. (2006). Water management for major urban centres. Water Res. Devt. 22(2):183-197.

[12] WHO/UNICEF (2013). Joint Monitoring Programme for Water Supply and Sanitation: Progress on Drinking Water and Sanitation - 2013 Update. Geneva: WHO Press.

[13] Monney, I., Buamah, R., Odai, S. N., Awuah, E., Nyenje, P. M (2013). Evaluating access to potable water and basic sanitation in Ghana's largest urban slum community: Old Fadama, Accra. J. Envt. Earth Sci. 3(11):20-36.

[14] Osumanu, I. K. (2013). Health changes of urban poverty and water supply in Northern Ghana. In: Wagner JR (ed.), The Social Life of Water. New York \& Oxford: Berghahn Books, pp. 158-179.

[15] Owusu-Sekyere, E., Aasoglenang, T. A., Bonye, Z. S. (2014). Household water supply vulnerability in low income communities in Ghana: experiences from Aboabo in the Kumasi Metropolitan Area. Int. J. Envt. Prot. Pol. 2(1):9-18.

[16] Addo, K. K., Mensah, G. I., Bekoe, M., Bonsu, C., Akyeh, K. (2009). Bacteriological quality of schate water produced and solid in Teshie-Nungua suburbs of Accra, Ghana. Afr. J. Food Agr. Nutri. Devt. 9(4):1019-1030.

[17] Stoler, J., Weeks, R. J., Fink, G. (2012). Sachet drinking water in Ghana's Accra-Tema Metropolitan Area: past, present and future. J. Water, San. Hyg. Devt. 2(4):223-240.

[18] Osumanu, I. K. (2008). Private sector participation in urban water and sanitation provision in Ghana: Experiences from the Tamale Metropolitan Area (TMA). Envt. Mgt. 42:102-110.

[19] Suleiman, L., Cars, G. (2010). Water supply governance in Accra: authentic or symbolic. Water Pol. 12:272-289.

[20] Ahimah, J. K., Ofosu, S. A. (2012). Evaluation of the quality of sachet water vended in the New Juaben Municipality of Ghana. Int. J. Water Res. Envt. Eng. 4(5):134-138.

[21] Singh, A. I. (2006). Governing water wisely. UN Chron. 4:2425.

[22] Osumanu, I. K. (2010). Community involvement in urban water and sanitation provision: the missing link in partnerships for improved service delivery in Ghana". J. Afr. Std. Devt. 2(8):208-215.

[23] Bartram, J., Lewis, K., Lenton, R., Wright, A. (2005). Focusing on improved water and sanitation for health. Lancet, 365:810-812.

[24] Satterthwaite, D. (2004). The millennium development goals and poverty reduction". In: Satterthwaite, D. (ed.), The Millennium Development Goals and Local Processes: Hitting the Target or Missing the Point? London: International Institute for Environment and Development, pp. 7-46.

[25] O'Hara, S., Hannan, T., Genina, M. (2008). Assessing access to safe water and monitoring progress on MDG7 target 10 (access to safe water and basic sanitation): Lessons from Kazakhstan. Water Pol. 10:1-24.

[26] WHO/UNICEF (2005). Water for Life: Making it Happen. Retrieved on 18 July 2014. Available: http://www.wssinfo.org/pdf/JMPJ)5_text.pdf

[27] Ghana Statistical Service (2012). Ghana: Population and Housing Census 2010. Accra: Ghana Statistical Service.

[28] Ghana Statistical Service (2012). Ghana: Demographic and Health Survey 2008. Accra: Ghana Statistical Service. 